(C)2009 IEEE. Personal use of this material is permitted. However, permission to reprint/republish this material for advertising or promotional purposes or for creating new collective works for resale or redistribution to servers or lists, or to reuse any copyrighted component of this work in other works must be obtained from the IEEE. 


\title{
Blocking Online Advertising - A State of the Art
}

\author{
Ashish Kumar Singh and Vidyasagar Potdar \\ Digital Ecosystems and Business Intelligence (DEBI) Institute \\ Curtin University of Technology \\ ashish.ism.cse@gmail.com v.potdar@curtin.edu.au
}

\begin{abstract}
Online advertising has emerged as one of the major business models on the Internet. Publishers rely on the online revenue generated from advertising to offer many free services. However, it has become evident that online advertisements are now becoming quite intrusive and also consume a lot of valuable bandwidth to download zero-caching ads and flash or video ads. As a result many users are now using ad-blocking software to make their Internet surfing more enjoyable. The main contribution of this paper is as follows - it attempts to identify the main reasons why internet users want to block online ads; it also critically evaluates several existing ad-blocking techniques and conducts an experiment to measure the amount of bandwidth used by online advertisements relative to the actual content. The paper concludes by outlining future research directions.
\end{abstract}

\section{INTRODUCTION}

The growth of Internet is fuelled by the heavy adoption of online advertisements. Online advertisements became inevitable after money and products started flowing through optical lines. Market and customers are now available on web and so do the advertisements. Online advertising aims at increasing sales by making the viewers of a web page notice the advertised products, along with the marketing information related to it, so as to entice them into buying the product [1].

FIGURE I

DIFFERENT TYPES OF ONLINE ADVERTISEMENTS

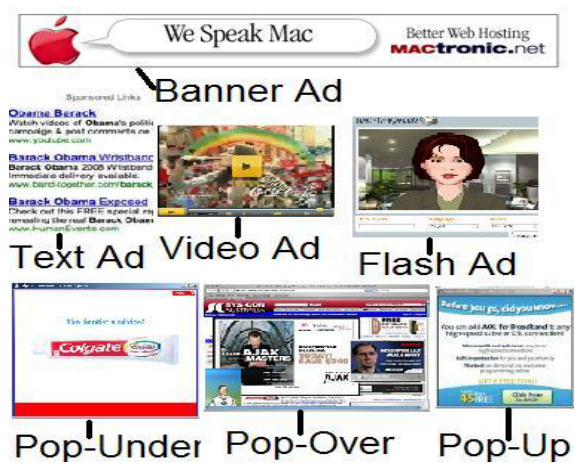

Online advertisements can be in many forms, viz., text, banner, flash, pop-up, pop-under, floating, polite, wallpaper, expanding, mobile, video and map ad. They can be viewed along with search results, in emails or often embedded in web pages. Advertisers create their customers by using the services provided by other sites (publishers). This comes at a cost that the advertiser pays to the publisher. Advertising is purchased as per following models:

FIGURE II

DifFERENT AD PURCHASE MODELS

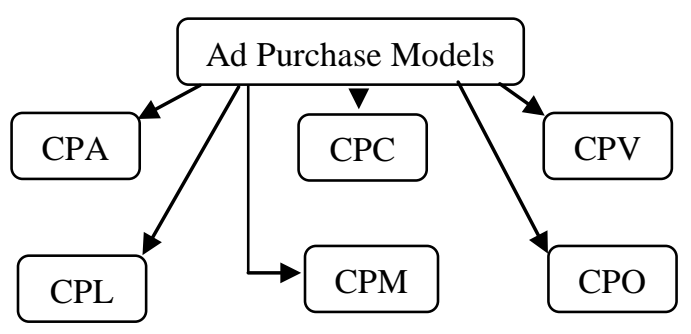

CPC (Cost Per Click) or PPC (Pay Per Click) Advertisers pay only when a user clicks on their ad and gets directed to their webpage. So, they pay according to the number of clicks [2].

CPM (Cost Per Thousand Impressions) - Advertisers are supposed to pay as per the number of times their ads have been shown to the users. It is generally paid per thousand impressions [2].

CPV (Cost Per Visitor or View) - Advertisers pay every time a visitor is directed to their site [2].

CPA (Cost Per Action or Acquisition) - Advertisers pay only for those visitors who are directed through the publisher's webpage to the advertiser's webpage and complete a transaction, such as a purchase or a sign-up [2].

CPL (Cost Per Lead) - Similar to CPA, in CPL the advertiser pays for those users who perform some action, which the advertiser feels will lead to some sale [2].

CPO (Cost Per Order) - Similar to CPA, the advertiser pays each time an order is placed by the user [2].

Nielsen/NetRatings concluded a four year study in 2007 that found a 37 percent increase in the time spent viewing content such as news and online videos [3]. Exploiting this change in the web users' attitude, publishers are now delivering content based on streamlined content models rather than static ones (that require reloading of pages). Thus, the time spent viewing a webpage can be a better parameter for the Ad Purchase model.

Even if viewers do not click on an ad, they familiarize with advertised product and develop an opinion about it. This phenomenon, in psychology, is termed as Exposure Effect [4]. To exploit this effect, advertisers try to publish their ads on as many sites as possible and use intrusive manners to attract the attention of viewers. They resort to types of ads such as pop-up and pop-under, which force viewers to see the advertisements [5].

It was earlier estimated that online advertisement would not be able to survive for long and bundling of advertisements 
with content would soon lose its importance [6]. This was proved with services like Google AdSense, Doubleclick etc. online advertising is now a multi-billion dollar industry.

The birth of intrusive online advertising led to the evolution of ad blocking techniques. Ad blocking has always been a controversial topic with many voicing for as well as against it. Some even called ad-blocking as theft of resources [7]. Ad blocking softwares can kill the online ad industry, having an estimated turnover of $\$ 40$ billion a year [8]. Publishers would lose their earnings if the ads were blocked [9].

In the following sections, we expand on this idea and outline the main reasons why we need to block ads. This is followed by a brief discussion on tools and techniques available for blocking ads in section 3. Section 4 then mentions the techniques used to bypass ad-blocking. Section 5 outlines the experiment results to determine how effective ad-blocking might prove to be. Section 6 provides a discussion and Section 7 outlines open research questions and concludes in section 8.

\section{REASONS TO BLOCK ADS}

As mentioned earlier online ads can be both, useful as well as annoying. Though online advertising is the main business model on the web at the moment, there are several reasons why blocking ads can be practical [10-12]. These reasons are now explored in more detail.

\section{A. Preventing Malware Infection}

Malware is malicious software written with the sole intention of damaging or infiltrating a computer system without the explicit permission of the owner [13]. Malware is not only annoying, but can cause data loss, destroy files on the hard disk, vandalize web pages, corrupt file systems or take control of a user's computer and use it for illegal purposes.

So, by preventing malware, all the above mentioned problems can be addressed. Online advertisements have become the prime target of malwares as they provide an easier and much efficient way to infect a large audience. Malware can be spread in primarily two ways [13]. First is by hacking into a publisher's site and inserting code behind some content of the page and second is by forming affiliate ad networks with the sole intention of spreading malware. In such networks, network operators are paid according to the number of infections spread [13].

\section{B. Psychological Impacts}

The second reason to block ads is its negative effect on the users' psychology. Psychology of the users is intensely affected by online advertisements. Many people spend maximum time of their day sitting before their system and surfing the net. The psychological impacts of ads are immense for such people. The top 4 metropolitan cities of
India surf the net for an average of 547.7 minutes per week $[14,15]$. In the US, people are spending more time on the net than on reading newspapers, listening to recorded music or watching movies [16]. Zanot (1984) says that accrual of ads urges users to avoid ads in traditional media $[17,18]$, clusterbomb approach has been identified as a reason for reduction in the responsiveness of users to internet ads [17, 18]. Benway (1999) found "banner blindness," tendency of internet users' to avoid fixing their eyes on anything that looks like a banner ad, as a phenomenon referenced frequently to demonstrate the ill aspects of internet advertisements [17, 19]. Another psychological impact is reduced level of retention of both, content and advertisement $[20,21]$. Users generally visit a website with the intention of getting some useful information but eventually walks away with a part of the content's information and a part of the advertisement's information mixing up in their minds. The advertisement's information comes at the cost of the content's information and hence, retention is affected.

TABLE I

RANKING ADS BASED ON THEIR LEVEL OF INTRUSIVENESS

REPRODUCED FROM: HTTP://WWW.USEIT.COM/ALERTBOX/20041206.HTML [23]

\begin{tabular}{|l|c|}
\hline \multicolumn{1}{|c|}{ Design Element } & $\begin{array}{c}\text { Users Answering } \\
\text { "Very Negatively" } \\
\text { or "Negatively" }\end{array}$ \\
\hline Pops-up in front of your window & $95 \%$ \\
\hline Loads slowly & $94 \%$ \\
\hline Tries to trick you into clicking on it & $94 \%$ \\
\hline Does not have a "Close" button & $93 \%$ \\
\hline Covers what you are trying to see & $93 \%$ \\
\hline Doesn't say what it is for & $92 \%$ \\
\hline Moves content around & $92 \%$ \\
\hline Occupies most of the page & $90 \%$ \\
\hline Blinks on and off & $87 \%$ \\
\hline Floats across the screen & $79 \%$ \\
\hline Automatically plays sound & $79 \%$ \\
\hline
\end{tabular}

Other than retention, irritation is also an important psychological factor that can be reduced by blocking ads. Blocking ads is essential to keep the users focused on what they are actually looking for. When a user visits a website $\mathrm{s} /$ he is not interested in the ads, but still is bombarded with them [22]. Jakob (2004) found in his survey that pop-ups are the most annoying kind of ads, followed by slow-loading ads. Table I shows the results of this study [23].

\section{Bandwidth Consumption}

Other than having adverse psychological impacts, ads also consume network bandwidth. This in turn reduces the available bandwidth for downloading useful content leading to increased download time. This was not the case in the past when ads only had simple text or small images. However, in the current state of the web, ads are more complicated since they use high quality pictures, flash, videos, etc which takes more time to download than the content of the page [11]. For slow internet connections, ads make this scenario even worse. 
TABLE II

AD BLOCKING ON DILBERT.COM

REPRODUCED FROM: HTTP://ADBLOCKPLUS.ORG/BLOG/ANATOMY-OF-ADS $[24]$

\begin{tabular}{|l|c|c|c|c|}
\hline & $\begin{array}{c}\text { with } \\
\text { caching, } \\
\text { with ads }\end{array}$ & $\begin{array}{c}\text { with } \\
\text { caching, } \\
\text { without ads }\end{array}$ & $\begin{array}{c}\text { without } \\
\text { caching, } \\
\text { with ads }\end{array}$ & $\begin{array}{c}\text { without } \\
\text { caching, } \\
\text { without } \\
\text { ads }\end{array}$ \\
\hline $\begin{array}{l}\text { amount of } \\
\text { data } \\
\text { transfered, } \\
\mathrm{kB}\end{array}$ & $\begin{array}{c}22-60 \\
(40)\end{array}$ & $\begin{array}{c}0-36 \\
(11)\end{array}$ & $\begin{array}{c}675-707 \\
(680)\end{array}$ & $\begin{array}{c}204-205 \\
(205)\end{array}$ \\
\hline $\begin{array}{l}\text { time } \\
\text { required, } \\
\text { seconds }\end{array}$ & $\begin{array}{c}2.6-5.4 \\
(3.5)\end{array}$ & $\begin{array}{c}0.0-1.2 \\
(0.3)\end{array}$ & $\begin{array}{c}6.2-8.4 \\
(7.1)\end{array}$ & $\begin{array}{c}6.0-8.1 \\
(6.7)\end{array}$ \\
\hline $\begin{array}{l}\text { number of } \\
\text { servers } \\
\text { contacted }\end{array}$ & $\begin{array}{c}6-8 \\
(6.7)\end{array}$ & $\begin{array}{c}0-1 \\
(0.5)\end{array}$ & $\begin{array}{c}8-9 \\
(8.9)\end{array}$ & 1 \\
\hline $\begin{array}{l}\text { number of } \\
\text { URLs } \\
\text { requested }\end{array}$ & $\begin{array}{c}12-13 \\
(12.5)\end{array}$ & $\begin{array}{c}0-1 \\
(0.5)\end{array}$ & $\begin{array}{c}72-77 \\
(73.2)\end{array}$ & 55 \\
\hline
\end{tabular}

Palant (2007) experimented on dilbert.com and found that $32 \%$ of space is occupied by ads while just $22 \%$ of space contains the actual content; the remaining space is used for navigation [24]. Table II outlines the actual results. Networking side shows even worse effects of ads. Ads triple the amount of data downloaded to view a page and ads with zero caching are the worst ones, as they are required to be downloaded each time the page is viewed or refreshed and hence, they deteriorate the available bandwidth [24].

\section{Mobile Advertising}

With the arrival of mobile devices capable of accessing Internet, advertisements have also crawled into mobile devices [25-28]. Advertisements pose a much greater threat in mobile devices because of several reasons like available screen size, the level of intrusiveness and the battery consumption.

Available screen size - The small available screen size of mobile devices requires that things to be viewed be judiciously decided, so as to minimize wastage of screen space. People generally treat ads as worthless, unless they provide some information they are looking for [29]. Hence, ads on mobiles waste the available screen space. Also, advertisements on mobiles makes it extremely difficult for users to view pages as a lot of scrolling is required to reach the desired content.

Intrusive nature - Wehmeyer (2007) defines intrusiveness as psychological reaction caused by interference with consumers' cognitive processes [30]. It becomes very annoying when someone is disturbed while doing some important work [30]. Melody (2004) found that users generally have a negative attitude towards mobile advertising, except where they have given their explicit consent [28]. The arrival of ads causes intrusion as it is announced by some sound or vibration on the mobile device. Even before the message is read, the user is disturbed [30]. So, even if the ad contains useful information, it first creates intrusion [30]. This is much more intrusive than other forms of advertising. SMSs can be even more disturbing if they arrive during the late hours, during a meeting or when the user is already in a disturbed state of mind.

Battery consumption - Battery consumption is another factor which makes mobile advertising a woe for users. The arrival of ads consumes battery and might also disturb users. Even on viewing some amount of battery is consumed. So ads reduce the available back up of mobile devices for useful purposes.

\section{E. Ethics}

Ethics is a system, which incorporates right conduct and good life [31, 32]. It is the study of right and wrong, good and bad [32]. Ethics of online advertising is about finding out whether or not it is right to place ads on a particular site. Obviously, the answer to this question has to be decided by the users [32-34]. It is definitely not a problem to place ads within the pages as long as they do not become annoying. But the moment a limit is crossed, it can unleash the wrath of its dark side and make users turn against it [29]. Michelle (2002) referred to a survey of Australian web publishers by AC Neilsen, which found that about $90 \%$ of publishers where willing to heed to any advertising technique just to keep the advertisers fascinated [35]. Porn ads raise a big question on the ethics of online advertisements as it is not just adults who use internet but kids too [36]. The Chinese Internet Authority feels Internet content such as pornography must be regulated [36].

According to survey conducted by Netcraft in June 2008, there are more than 172,338,726 sites on internet [37] and since each site has a number of pages, it is very difficult for users to glean through all this information in detail. Hence, they just look for some major areas on the webpage to get the required information. Eye tracking research identified the patterns that users' eyes follow while scanning a page and the different features that get noticed by users' eyes. In order to identify the patterns, heat maps are used that depict what portion of a page is generally viewed by users. An example of a heat map is shown in Fig. III.

FIGURE III 
HEATMAP OF A SITE. RED PORTION DENOTES THE MOST VIEWED AREA FOLLOWED BY YELLOW, FOLLOWED BY BLUE AND THE GREY AREA IS LEAST VIEWED.

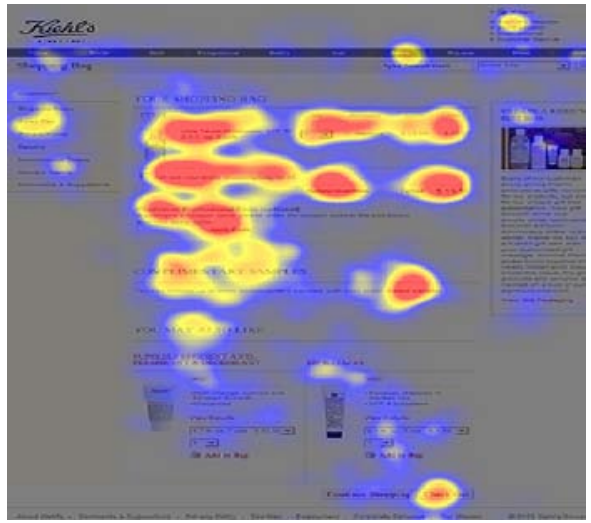

If somehow publishers start putting ads in the red zones (by disguising ads as contents), a user will end up reading about different vacation packages, new models of cars etc., instead of what they were actually looking for. Apart from spoiling his mood, this will certainly put off any intention of the user to revisit the site [38].

FIGURE IV

HEAT MAPS SHOWING THAT ANNOYING ADS ARE GENERALLY IGNORED BY THE USERS [39]
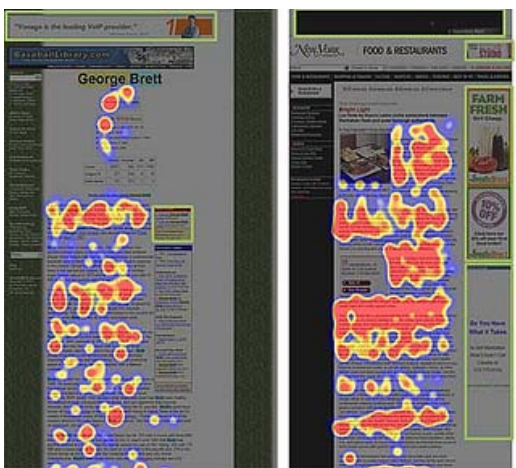

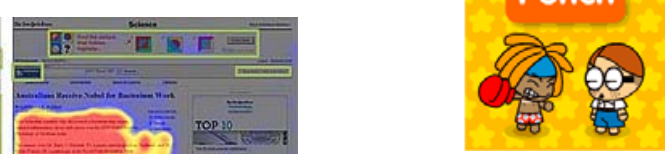

Figure V

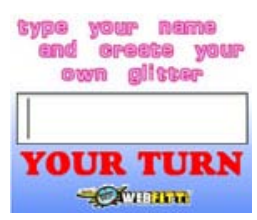

Figure VI

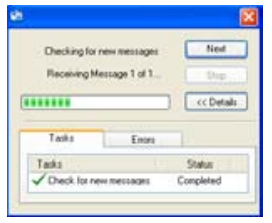

Figure VII
Fig. $\mathrm{V}$ gives the impression that on clicking the Punch button, the girl will punch the boy, but on clicking, the user is directed to a different page. Cartoon characters are used to attract children who generally like playing games on the net. Fig. VI gives the impression that by clicking in the text box, some name can be entered to create glitter but it throws the user to some other site. Fig. VII shows a close button (X) that any user would click on to get rid of the message, but clicking it opens a different site.

In this section, we tried to cite reasons as to why online ad-blocking is required. We cited many reasons supporting online ad-blocking such as extra bandwidth consumption, negative impact on the psychology of users, spreading of malware, use of additional memory, deterioration of mobile services, tricking users into clicking on ads, etc. We now discuss some tools that can be used to block ads. Hence it makes sense to block such ads.

\section{TOOLS AND TECHNIQUES FOR BLOCKING ADS}

After ads started irritating web users, ad blocking techniques were developed [11]. The following techniques not only aim at avoiding distractions caused by ads but also save a good amount of bandwidth, thus reducing the download time. One of the most popular ad-blocking 
softwares is the AdBlock Plus ${ }^{\mathrm{TM}}$ plug-in used in the Firefox ${ }^{\mathrm{TM}}$ web browser. It comes with a default list of adURLs to be blocked. Some filter lists can also be subscribed to, which contain updated and much larger lists of ad-URLs. It also enables web users to filter those contents of the page, which they feel are not adding any value. So the next time they visit the page, the filtered contents are not displayed. It also supports wildcards, such as ' $*$ ' to make the blocking more generic [48]. Sites like "URLfilterDB" and "EasyList" evolved to simplify the tedious task of identifying and adding ad-URLs to the filter lists. They provide updated lists of ad-URLs, thus making it convenient for the user to get rid of advertisements [49, 50]. A similar solution for IE is also available from AdBlockPro.com, which allows users to block ads on IE, the only difference being that the former is free but the latter is not [45]. Other than the client side tools like AdBlock Plus ${ }^{\mathrm{TM}}$ and AdBlock Pro ${ }^{\mathrm{TM}}$, server side tools, such as Privoxy ${ }^{\mathrm{TM}}$, are also available. Privoxy $^{\mathrm{TM}}$ can provide not only a server side solution but can also be used on the client side. Privoxy ${ }^{\mathrm{TM}}$ can also manipulate the pages requested by the users and thus holds a great potential to deal with ads intelligently. But all this is done at the cost of some CPU usage.
ZCA, if cached, can reduce the bandwidth consumption by a large extent, but currently, there is no tool that can efficiently do this.

\section{Critical Evaluation of Existing Ad Blocking Tools}

Table III lists some of the existing ad-blocking tools. Though AdBlock Plus ${ }^{T M}$ is a very good option, a lot many improvements are still possible to make the ad-blocking more flexible and convenient. We studied 12 different ad blocking tools, as shown in Table III. These tools were evaluated along 9 criteria, viz.:
1. Kills Pop-ups
2. Stops Java Scripts
3. Blocks Banner ads
4. Blocks Flash Ads
5. Blocks images of specific sizes
6. URL Filter (manual)
7. URL Filter (with default or subscribed lists)
8. Blocks zero- caching ads
9. Automatic ad-URL identification (based on content).

TABLE III List of Ad-Blocking Tools

\begin{tabular}{|c|c|c|c|c|c|c|c|c|c|}
\hline & $\begin{array}{l}\text { Kills Pop- } \\
\text { ups }\end{array}$ & $\begin{array}{l}\text { Stops } \\
\text { Java } \\
\text { Scripts }\end{array}$ & $\begin{array}{l}\text { Blocks } \\
\text { Banner } \\
\text { ads }\end{array}$ & $\begin{array}{l}\text { Blocks } \\
\text { Flash } \\
\text { Ads }\end{array}$ & $\begin{array}{l}\text { Blocks } \\
\text { images of } \\
\text { specific } \\
\text { sizes }\end{array}$ & $\begin{array}{l}\text { URL } \\
\text { Filter } \\
\text { (manual ) }\end{array}$ & $\begin{array}{l}\text { URL Filter } \\
\text { (with default } \\
\text { or subscribed } \\
\text { lists ) }\end{array}$ & $\begin{array}{l}\text { Blocks } \\
\text { zero- } \\
\text { caching } \\
\text { ads } \\
\end{array}$ & $\begin{array}{l}\text { Automatic ad-URL } \\
\text { identification } \\
\text { (based on content) }\end{array}$ \\
\hline AdBlock [48] & Yes & Yes & Yes & Yes & Yes & Yes & No & No & No \\
\hline $\begin{array}{l}\text { AdBlock Plus } \\
\text { [50] }\end{array}$ & Yes & Yes & Yes & Yes & Yes & Yes & Yes & No & No \\
\hline ufdbGuard [49] & Maybe & Maybe & Maybe & Maybe & Maybe & Yes & Yes & No & No \\
\hline Adarmor [51] & Yes & Yes & Yes & Yes & No & Yes & Yes & No & No \\
\hline STOPzilla [52] & Yes & Yes & No & No & Maybe & No & No & No & No \\
\hline Ad Blocker [53] & Yes & Maybe & Yes & Yes & Maybe & Maybe & Yes & No & No \\
\hline $\begin{array}{l}\text { IE7 Adblock Pro } \\
\text { [54] }\end{array}$ & Yes & Yes & Yes & Yes & Maybe & Yes & No & No & No \\
\hline $\begin{array}{l}\text { Super Adblocker } \\
\text { [55] }\end{array}$ & Yes & Maybe & Yes & Yes & No & No & No & No & No \\
\hline $\begin{array}{l}\text { Serenity ad } \\
\text { blocker [56] [57] }\end{array}$ & Yes & Yes & Yes & Yes & Maybe & NA & Yes & No & No \\
\hline AdShield [58] & Yes & Yes & Yes & Yes & Maybe & Yes & Yes & No & No \\
\hline \multicolumn{10}{|c|}{ Server Side Tools } \\
\hline Privoxy [59] [60] & Yes & Maybe & Yes & Maybe & Maybe & Yes & Maybe & No & No \\
\hline
\end{tabular}

All aforementioned tools basically look for the terms 'ad' or 'ads' or 'click' in the URLs present on a web page to identify advertisement URLs and selectively block them. The heuristic generally used for such techniques is that advertisements are not directly embedded in the web page but are invoked through their URLs at the time of page download. By keeping track of all the URLs from where data packets have been downloaded while viewing a page, lists of URLs can be formed per page and users can then decide which URLs they want to filter.

Almost all of the available ad-blocking softwares are capable of killing pop-ups, as pop-up is the most hated advertisement technique [61]. There are more than 135 pop-up blockers available [61]. Another category of ads is Zero Caching Ads (ZCA). ZCAs are those ads that cannot be cached by the browser. Thus, every time they are viewed, the same amount of bandwidth is consumed.
Of the 12 tools that we investigated, we found that a majority can potentially block banner ads, flash ads, popups and images, but cannot do this intelligently. If keywords like ad or click are not present in the ad-URL and that URL has not been manually added to the filter list, these ad-blockers would not be able to block it. Secondly, the existing tool set cannot automatically detect URLs likely to be advertisements; most of the current techniques only rely on looking for keywords like ad or ads in the URL. If the publishers start using different keywords, these systems would fail easily.

Based on the investigation, we found that at the moment, AdBlock Plus ${ }^{\mathrm{TM}}$ offers the best solution to the problem. Anne and Declan (2007) claimed in 2007 that about 2.5 million people use AdBlock Plus ${ }^{\mathrm{TM}}$ [62] although the latest figure is around 22 million [63] (about $1.5 \%$ of the net users) [64]. This is because AdBlock 
Plus $^{\mathrm{TM}}$ is not only easy to use but its filter list can be updated with most of the advertisement URLs by subscribing to the filter lists. As of today, the best approach to effectively block ads is to have an updated filter list containing the maximum possible advertisement URLs. Now that we have seen how ad-blocking is possible, we now look at ways that can be used to bypass ad-blocking tools.

\section{TECHNIQUES TO BYPASS AD BLOCKERS}

In response to ad-blocking softwares, web publishers developed some techniques that can be used to bypass adblockers. We will discuss some of these approaches in this section.

\section{A. Java Script}

ViButX (2007) developed a java script to bypass ad blockers [65]. The script moves all the content of a page to a variable and then generates a unique random identity for the page containing ad to prevent FireFox ${ }^{\mathrm{TM}}$ users from applying custom CSS to hide both ad and content. After creating the random id, it puts back the content of page into its actual position and thus bypasses AdBlock Plus ${ }^{\mathrm{TM}}$ easily [65].

\section{B. Subscription based Business Model}

Publishers might also resort to the subscription based business model to suppress ad blocking. In this business model, users have to subscribe to the publishers' site, which may or may not be free. By doing so, the revenue earlier generated through ads is now generated through subscription fees. Hence, users will have to pay for viewing the publishers' website. This may threaten the free nature of the Internet. Users would not be able to get loads of information by just surfing the net, but will have to spend to subscribe. Also, as users would not subscribe to many websites, the information that would reach them might not be as diverse as what they get today.

\section{Blocking Users}

Publishers might also block users from viewing their website if they find that ad-blockers are being used. This may directly or indirectly force users to give up adblocking techniques. For example, a publisher might discover that his revenue generated from ads, is going down because most of the users are using ad-blocking techniques. As a result the publisher might start selectively blocking those users who access the website with ad-blocking software. Users will then have to give up ad-blocking tools to view the publishers' site or visit some other sites.

\section{Keyword Avoidance}

Most ad-blockers scan the requested URLs for some terminology, such as ad or ads or click commonly used in ad URLs. By closely examining an ad-blocker, the key points taken into consideration in determining whether or not to block a particular URL or image can be found out [66]. For example, AdBlock Plus ${ }^{\mathrm{TM}}$ can be bypassed by avoiding the use of "ad" and "click" like keywords in file names [66].

\section{E. Random Image Sizes}

As publishers generally devote a fixed portion of their page to advertisements, the size of image ads is generally the same. This image size is also one of the key factors that ad-blockers check in order to determine whether an image is an ad or not. By using slightly altered image sizes, such as sizes other than $468 \times 60,125 \times 125$, etc., ad-blockers that check image sizes can be bypassed [66].

\section{F. Setting up Local Ad Servers}

Ad-blockers only check the content coming from URLs other than the URL requested by the user. So, publishers may start embedding the ads into their page or may set up local ad servers. However, the drawback of this approach would be the bandwidth of the content provider would increase significantly. Secondly, it would not be sustainable for the publishers to maintain their own ad network since that is not their core competency. Hence, doing so snatches away the flexibility available with the publishers, but can potentially challenge ad blockers.

\section{G. Critical Evaluation}

Though all of the above mentioned techniques to bring down ad blocking are effective, none of them is good enough to completely knock it out. Subscriptionbased business model and blocking users certainly go a long way in forcing users to give up any attempt of blocking ads, but are still not quite feasible. This is because, to do so, publishers will have to change the whole business model and hence, the definition of Internet Marketing. This, as a result, might push the users away. Generating Unique Random Identity for the page might also not be capable of bypassing ad-blockers as it will easily be noticed by the ad-blocker developers. Some adaptations might make ad-blockers capable enough to fool the script. One such technique could be to divert the ads to different IPs instead of blocking them. Although ad-blocking may be considered as a revenue reducer, publishers should consider other aspects such as nonrevenue based benefit that it can bring to their portal. For example, if a user using ad-block visits their website and likes it because of no interfering ads and the good content available, he may put a link of their website on his blog. This can drive more user traffic to their website, who may or may not have ad-blockers installed.

\section{EXPERIMENTS}

We tested the effectiveness of ad blocking using AdBlock Plus ${ }^{\mathrm{TM}}$, EasyList ${ }^{\mathrm{TM}}$ (USA), Mozilla Firefox ${ }^{\mathrm{TM}}$ with zero cache memory and Bandwidth Monitor ${ }^{\mathrm{TM}}$. As mentioned previously, although ABP (AdBlock Plus) is good for blocking ads, even after using the EasyList filter 
list, it leaves many ads unchecked. We collected about 30 sites from "Most popular sites of Australia” and “Top 100 blogging sites of Australia”, meticulously scrutinized each site and added all advertisement URLs present in these sites to the filter list. We then simultaneously opened each site and recorded the bandwidth consumption on two different systems with almost same configuration, one with AdBlock Plus ${ }^{\mathrm{TM}}$ and other without it. Results show a great impact of intelligent ad blocking.

\section{FIGURE VIII}

Graph shows the bandwidth consumption for the system without any ad blocking tool.

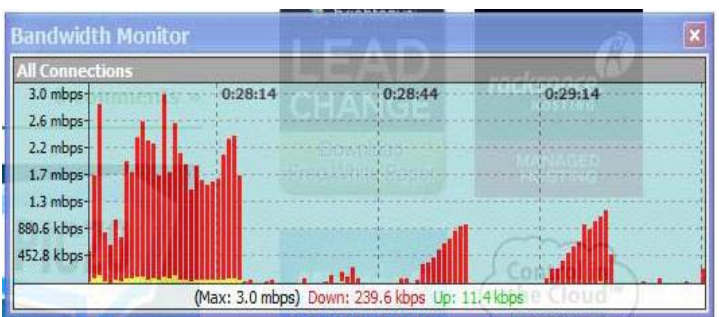

FIGURE IX

Graph shows the bandwidth consumption for system with an ad blocking tool.

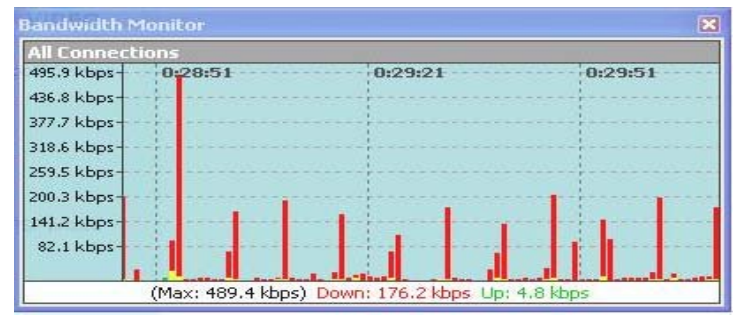

These graphs clearly show the difference caused by ad blocking. The table below gives a more clear idea.

TABLE IV

Table shows the exact figures of downloaded and uploaded data during our experiment.

\begin{tabular}{|c|c|c|c|}
\hline & \multicolumn{3}{|c|}{ With ads } \\
\hline & Downloaded & Uploaded & Total \\
\hline Total: & $35.04 \mathrm{MB}$ & $2.61 \mathrm{MB}$ & $37.65 \mathrm{MB}$ \\
\hline \multicolumn{4}{|c|}{ Without ads } \\
\hline & \multicolumn{4}{|c|}{ Uploaded } & Total \\
\hline & Downloaded & Upl & $24.45 \mathrm{MB}$ \\
\hline Total: & $22.92 \mathrm{MB}$ & $1.52 \mathrm{MB}$ & 2
\end{tabular}

Ad-blocking caused a $35.06 \%$ fall in the bandwidth usage. This percentage is sufficient to support the use of ad-blocking techniques.

As ads on a page are not constant, the bandwidth consumed by them also varies. This percentage thus keeps changing. We conducted the experiment twice and found that the percentage bandwidth consumption varied from $25 \%$ to $35.06 \%$. For some sites this percentage was immense while for others, it was quite small. Figure $\mathrm{X}$ shows the amount of bandwidth consumed for downloading content with and without ad-blocking software.

\section{FIGURE X}

The graph shows the difference in bandwidth consumption due to ads, for different sites included in our test.

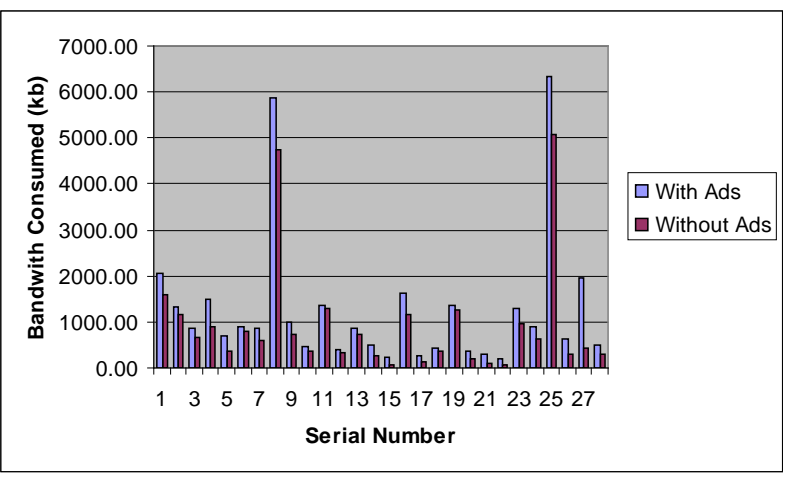

\section{DISCUSSION}

After discussing techniques of ad-blocking and techniques to block ad blocking, it has become quite essential to find some amiable way to sort out the problem. As mentioned above, publishers might not be able to sustain if ads were blocked by their users. Hence a change in business model is required. Publishers should not solely rely on web advertising as their only business model. If they are not in a position to use any other model successfully, they should at least tweak the advertising campaign so it does it is not annoying. For example, publishers can reduce the amount of ads displayed on the page, and consider how the end user would perceive their webpage. If the publisher is able to attract more visitors by reducing the number of ads and gain a competitive advantage, then this long term advantage will turn out to be much better then a short term gain by increased revenue. If this approach is not effective then publishers may attempt to enforce technologies that may block ad-blocking techniques. This can be done by issuing a message to ad-blocking users that they must not block the ads if they want to access the content of the page. On the other hand, if the servers start blocking content to those who use ad blocking techniques, there is a fair chance that the users may not return to that website assuming that the website is down or rely on Google Cache Surfing. Google cache surfing refers to accessing the desired websites via the Google Cache, instead of directly visiting them on their domain address. There are several tools already present that enable Google cache surfing. It can also be a good option if web hosts have slow response time due to limited available bandwidth. Other than that online advertizing 
using banner ads are vulnerable to banner blindness. This is because banner advertisement is one of the oldest and most famous forms of advertisement but this popularity has resulted in users easily neglecting these ads since they know where these ads are generally located and how they look like. By making ads that are not intrusive, but appealing to users and only directing relevant ads to users, the problem of people becoming blind to ads can be solved to a certain extent [41]; however it is still not a cure for this problem. Overall the publishers should aim at understanding their target audience. If they can cater to their needs in an ethical manner the likely hood of users resorting to ad-blocking may be reduced. The main reasons why users are relying on ad-blocking software is because the feel ads be intrusive. Hence one of the first step that should be taken is to make it less intrusive. Having said that in certain cases it is beyond the publisher's control of which ads are displayed. This is because many publishers subscribe to one of the available online ad services like Ad Sense. The only thing that publisher's can control is the location and the number of ads on a particular page. Publishers could undertake polling on the site to decide which ads are annoying. Based on this poll, ads can be blocked by the publisher itself. The main disadvantage with this model is that advertisers may resort to casting fake votes to save their advertisement, in which case some kind of feedback validation should be in place. The polling scheme might also not be appreciated by the users. This may thus not be practical. Given these issues with online advertizing the next section outlines the potential research direction that can be explored in this field of research.

\section{FUTURE RESEARCH DIRECTIONS}

This section outlines some of the open research issues that researchers may be interested in solving.

How to reduce the intrusive nature of ads? Ads become loathsome mostly because of the intrusion caused by them. The following suggestions can help an advertisement designer in designing non-intrusive ads. Use mild colors since bright colors attract the attention of the users and hence cause interruption [67]. Use slow animations since fast animations not only disturb the users but also put stress on their eyes.

How to decide the ratio between ads and content? The ratio between ads in a page and content of the page must be determined judiciously in order to keep ads within limits. Though this ratio is very important in determining whether ads are ethical or not, it is not the only aspect. Even a single ad can sometimes annoy a user. Such annoying ads are generally in the form of pop-ups, flash, pop-under, ads with sounds or moving ads. Hence identifying the threshold for the ratio between ads and content is an interesting research question.

How to detect URLs susceptible of being Ads? It would be good for both advertisers and publishers, to devise some method which would automatically decide whether ads from a URL are annoying or not. If the ads seem to be annoying according to certain heuristics, they can be blocked by the publisher itself. This model might ease the arms race going between the ad supporters and its opponents.

How to cache Zero-Caching Ads(ZCA)? ZCAs, if cached, can reduce the bandwidth consumption by a large extent. But currently, there is no tool that can efficiently do this. Developing a technique that can enable caching of ZCA is also very challenging an interesting research question.

Studying the impacts of Ad repositioning Advertisement repositioning can work wonders in improving users' experience on websites. All ads can be moved below the useful content so that users are not disturbed by the ads while reading or searching for the actual content. This might solve the problem of intrusion created by ads, but, it would not save the bandwidth consumed by ads.

Can ads be blurred in real time? By blurring ads their potential intrusiveness can be reduced as they would not be as eye catching.

We listed some of the open research direction in the field of ad-blocking. This is by no way a comprehensive list of open research questions, but the authors assume this is a starting point and further research questions would emerge when these questions are being addressed.

\section{CONCLUSION}

Online advertising, which came up as a major business model on internet, has also produced a number of side effects. Apart from generating revenue for publishers, it is also spreading malware, misleading users, creating intrusion, wasting expensive bandwidth, etc. In this paper, we discussed about various aspects of online advertising. This paper attempted to identify the main reasons as to why internet users want to block online ads. It evaluated different ad-blocking techniques based on nine criteria. The paper also conducted an experiment to measure the amount of bandwidth consumed by online advertisement relative to the actual content. In the future we will work towards detecting susceptible Ad-URLs and propose a framework for automated ad-repositioning.

\section{REFERENCES}


1. Danaher, P.J. and G. Mullarkey, Factors Affecting Online Advertising Recall: A Study of Students. Journal of Advertising Research, 2003. 43(03): p. 252-267.

2. Online Advertising. 2007 [cited 28/07/2008]; Available from: http://en.wikipedia.org/wiki/Online_advertising.

3. Half of Web time spent viewing content: study. 2007 [cited 28/07/2008]; Available from: http://www.reuters.com/article/technologyNews/idUSN13351661200708 13.

4. Exposure effect. 2008 [cited 2008 28/07/08]; Available from: http://en.wikipedia.org/wiki/Exposure_effect.

5. Robinson, H., A. Wysocka, and C. Hand, Internet advertising effectiveness. Advertising, 2007. 26(4): p. 527-541.

6. Y. Yuan, J.P.C.a.S.R., The relationship between advertising and content provision on the Internet. European Journal of Marketing, 1998. 32(7/8): p. 11.

7. Soghoian, C. Who blocks the (ad) blockers? 2007 [cited 2008 28/07/08]; Available from: http://news.cnet.com/8301-13739_39770502-46.html.

8. Zykova, A. Ad-blocking software may threaten \$40-billion-a-year online ad industry. 2008 [cited 2008 28/07/2008]; Available from: http://www.editorsweblog.org/multimedia/2008/06/adblocking_software _may_threaten_40billi.php.

9. What's Wrong With Blocking Ads? 2007 [cited 2008 28/07/2008]; Available from: http://blog.mises.org/archives/007149.asp.

10. Burns, K.S. and R.J. Lutz, Web users' perceptions of and attitudes toward online advertising formats. International Journal of Internet Marketing and Advertising, 2008. 4(4): p. 281-301.

11. Cho, C.H. and U.T.A. as, WHY DO PEOPLE AVOID ADVERTISING ON THE INTERNET? Journal of Advertising, 2004. 33(4): p. 89-97.

12. Yaveroglu, I. and N. Donthu, Advertising Repetition and Placement Issues in On-Line Environments. Journal of Advertising, 2008. 37(2): p. 31-44

13. Ed Skoudis, L.Z., Malware: Fighting Malicious Code. 2003: Prentice Hall PTR. 672

14. 'Older people surf the longest'. 2006 [cited 2008 28/07/2008]; Available from: http://www.thehindubusinessline.com/2006/10/20/stories/200610200128 0900.htm.

15. Manchanda, P., et al., The Effect of Banner Advertising on Internet Purchasing. Journal of Marketing Research, 2006. 43(1): p. 98108.

16. More time spent on Net than newspapers. 2007 [cited 2008 28/07/2008]; Available from: http://english.people.com.cn/90001/90781/90877/6235819.html.

17. Cheon, H.J., Why do people avoid advertising on the Internet? Journal of Advertising 2004 33(4): p. 89 - 97.

18. Zanot, E.J., Public Attitude Toward Advertising: The American Experience. International Journal of Advertising, 1984. 3(January): p. 315.

19. Benway, J.E., Banner Blindness: What Searching Users Notice and Do Not Notice on the World Wide Web. 1999, Rice University.

20. S. McCoy, A.E., D. Galletta and P. Polak, The effects of online advertising. Communications of the ACM, 2007. 50(3 ): p. 84 - 88

21. Mitchell, A. and A. Valenzuela, How Banner Ads Affect Brand Choice Without Click-Through. Online Consumer Psychology:
Understanding And Influencing Consumer Behavior in the Virtual World, 2005.

22. Smith, A.D., Exploring advergaming and its online advertising implications. International Journal of Business Information Systems, 2007. 2(3): p. 298-311

23. Nielsen, J. The Most Hated Advertising Techniques. 2004 [cited 2008 28/07/2008]; Available from: http://www.useit.com/alertbox/20041206.html.

24. Palant, W. Anatomy of ads 2007 [cited 2008 28/07/2008]; Available from: http://adblockplus.org/blog/anatomy-of-ads.

25. Tsang, M.M., S.C. Ho, and T.P. Liang, Consumer Attitudes Toward Mobile Advertising: An Empirical Study. International Journal of Electronic Commerce, 2004. 8(3): p. 65-78.

26. Haghirian, P. and A. Inoue, An advanced model of consumer attitudes toward advertising on the mobile internet. International Journal of Mobile Communications, 2007. 5(1): p. 48-67.

27. Barnes, S.J. and E. Scornavacca, Mobile marketing: the role of permission and acceptance. International Journal of Mobile Communications, 2004. 2(2): p. 128-139.

28. Melody M. Tsang, S.-C.H., and Ting-Peng Liang, Consumer Attitudes Toward Mobile Advertising: An Empirical Study. International Journal of Electronic Commerce / Spring 2004,, 2004. 8(3): p. 65-78.

29. Marshall, J.A., INTERNET ADVERTISING: ARE WE BREAKING GROUND OR MOVING DIRT? 2005, University of Central Florida Orlando, Florida.

30. Wehmeyer, K., Mobile ad intrusiveness - The effects of message type and situation, in $20^{\text {th }}$ Bled eConference eMergence: Merging and Emerging Technologies, Processes, and Institutions, M.L. Markus, Editor. 2007: Slovenia. p. 76-84.

31. Ethics. 2008 [cited 2008 28/07/2008]; Available from: http://en.wikipedia.org/wiki/Ethics.

32. Austin, M.J. and M.L. Reed, Targeting children online: Internet advertising ethics issues. Journal of Consumer Marketing, 1999. 16(6): p. 590-602.

33. Rao, S. and P. Quester, Ethical marketing in the internet era: a research agenda. International Journal of Internet Marketing and Advertising, 2006. 3(1): p. 19-34.

34. Dahl, S., Ethics in online marketing: a case-based analysis of ethical issues in internet marketing. 2007.

35. Griffin, M. Web ways to ad insult to irritation. 2002 [cited 2008 28/07/2008]; Available from: http://www.theage.com.au/articles/2002/03/15/1015909904743.html.

36. Liang, G. See how the Chinese surf the 'Net. 2005 [cited 2008 28/07/08]; Available from: http://money.cnn.com/2005/11/17/technology/china_internet/index.htm.

37. June 2008 Web Server Survey. 2008 [cited 2008 28/07/2008]; Available from: http://news.netcraft.com/archives/web_server_survey.html.

38. Eyetracking Research. 2005 [cited 2008 28/07/2008]; Available from: http://www.useit.com/eyetracking/.

39. Nielsen, J. Banner Blindness: Old and New Findings. 2007 [cited 2008 28/07/2008]; Available from: http://www.useit.com/alertbox/banner-blindness.html.

40. McCollum, J. Online Advertising Sucks Because the Ads Suck. 2007 [cited 2008 28/07/2008]; Available from: http://www.technologyevangelist.com/2007/08/online_advertising_s.htm

41. Ad Blindness and Online Video 2008 [cited 2008 28/07/2008]; Available from: http://willvideoforfood.com/2008/02/14/ad-blindnessand-online-video/. 
42. Calisir, F. and D. Karaali, The impacts of banner location, banner content and navigation style on banner recognition. Computers in Human Behavior, 2008. 24(2): p. 535-543.

43. How to reduce memory usage of Yahoo Messenger. 2006 [cited 28/07/2008; Available from: http:/www.johntp.com/2006/07/29/how-toreduce-memory-usage-of-yahoo-messenger/.

44. How to remove all unwanted Yahoo Messenger Ads. 2006 [cited 2008 28/07/2008]; Available from: http://www.johntp.com/2006/06/04/how-to-remove-all-unwanted-yahoomessenger-ads/.

45. Remove Ads from Windows Live Messenger with A-Patch and Customize Messenger Options and Visualisation. 2006 [cited 2008 28/07/2008]; Available from: http://www.mydigitallife.info/2006/06/23/remove-ads-from-windowslive-messenger-with-a-patch-and-customize-messenger-options-andvisualisation/.

46. Smith, R.G., DECEPTIVE AND MISLEADING ON-LINE ADVERTISING BUSINESS PRACTICES. Communications Research Forum 2000, 2000.

47. Guangrong, R., The Negative Impact of the Internet and Its Solutions, in The Chinese Defense Science and Technology Information Monthly. 1998.

48. The AdBlock Project. [cited 2008 28/07/2008]; Available from: http://adblock.mozdev.org/.

49. URLfilterDB. [cited 2008 28/07/2008]; Available from: http://www.urlfilterdb.com/.

50. Adblock Plus: Save your time and traffic. 28/07/2008]; Available from: http://adblockplus.org/en/.

51. AdArmor Product Information [cited 2008 28/07/2008]; Available from: http://adarmor.abcwebtech.com/.

52. Anti-Spyware Made Easy. [cited 2008 28/07/2008]; Available from: http://www.stopzilla.com/products/stopzilla/home.do.

53. Ad Blocker - Stop pop-up windows, block ad sites, remove banners, image ads and flash ads. [cited 2008 28/07/2008]; Available from: http://www.cdkm.com/.

54. AdBlock Pro. [cited 2008 28/07/2008]; Available from: http://www.adblockpro.com/.

55. Stop Pop-Ups. Block Spyware. Be Safe. [cited 2008 28/07/2008]; Available from: http://www.superadblocker.com/.

56. Serenity Ad Blocker 0.96 [cited 2008 28/07/2008]; Available from: http://www.freewarefiles.com/Serenity-AdBlocker_program_21870.html.

57. Serenity Ad Blocker. [cited 2008 28/07/2008]; Available from: http://www.morpheussoftware.net/sab/.

58. AdShield. [cited 2008 28/07/2008]; Available from: http://www.ad-shield.com/.

59. Privoxy. 2008 [cited 2008 28/07/2008]; Available from: http://en.wikipedia.org/wiki/Privoxy.

60. Keil, F. pft - Privoxy-Filter-Test. 2007 [cited 2008 28/07/2008]; Available from: http://www.fabiankeil.de/sourcecode/pft/.

61. Pop-up Killer Review. 2005 [cited 2008 28/07/2008]; Available from: http://www.popup-killer-review.com/all-blockers.htm.

62. Anne Broache, D.M. Web ad blocking may not be (entirely) legal. 2007 [cited 2008 28/07/2008]; Available from: http://news.cnet.com/Web-ad-blocking-may-not-be-entirely-legal/21001030_3-6207936.html?tag=st.prev.

63. Palant, W. Adblock Plus 0.7.5.5. 2008 [cited 30/07/2008]; Available from: https://addons.mozilla.org/en-US/firefox/addon/1865.
64. Internet World Stats. 2008 [cited 30/07/2008]; Available from: http://www.internetworldstats.com/top20.htm.

65. ViButX. ByPass Ad Blockers. 2007 [cited 2008 28/07/2008]; Available from: http://www.webdesign.org/web/webprogramming/javascript/bypass-ad-blockers.11111.html

66. Fulton, M. Publishers: How To Bypass Ad Blocking Software. 2008 [cited 2008 28/07/2008]; Available from: http://www.dotsauce.com/2008/02/27/how-to-bypass-ad-block-software/

67. Moore, R.S., C.A. Stammerjohan, and R.A. Coulter, BANNER ADVERTISER-WEB SITE CONTEXT CONGRUITY AND COLOR EFFECTS ON ATTENTION AND ATTITUDES. Journal of Advertising, 2005. 34(2): p. 71-84. 